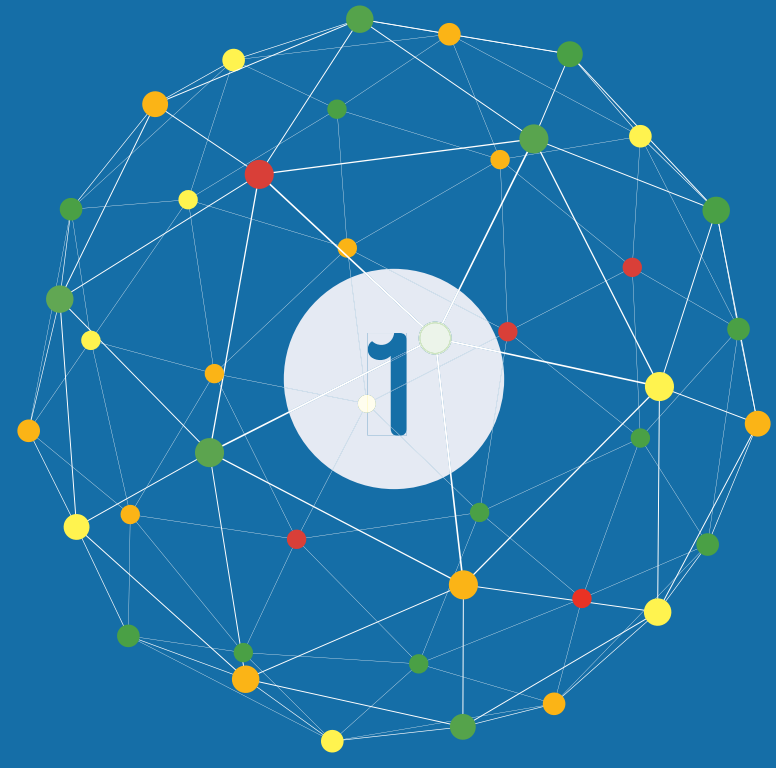

\title{
Increasing the fiscal space of developing countries to achieve the SDGs
}

